\title{
NAHDLATUL ULAMA: TELAAH HISTORI PERKEMBANGAN DAN GERAKAN DAKWAHNYA DI INDONESIA
}

\section{Siti Umi Taslima}

Mahasiswa Magister Pengembangan Masyarakat Islam UIN Imam

Bonjol, Padang, Indonesia

sitiumitaslima02@gmail.com

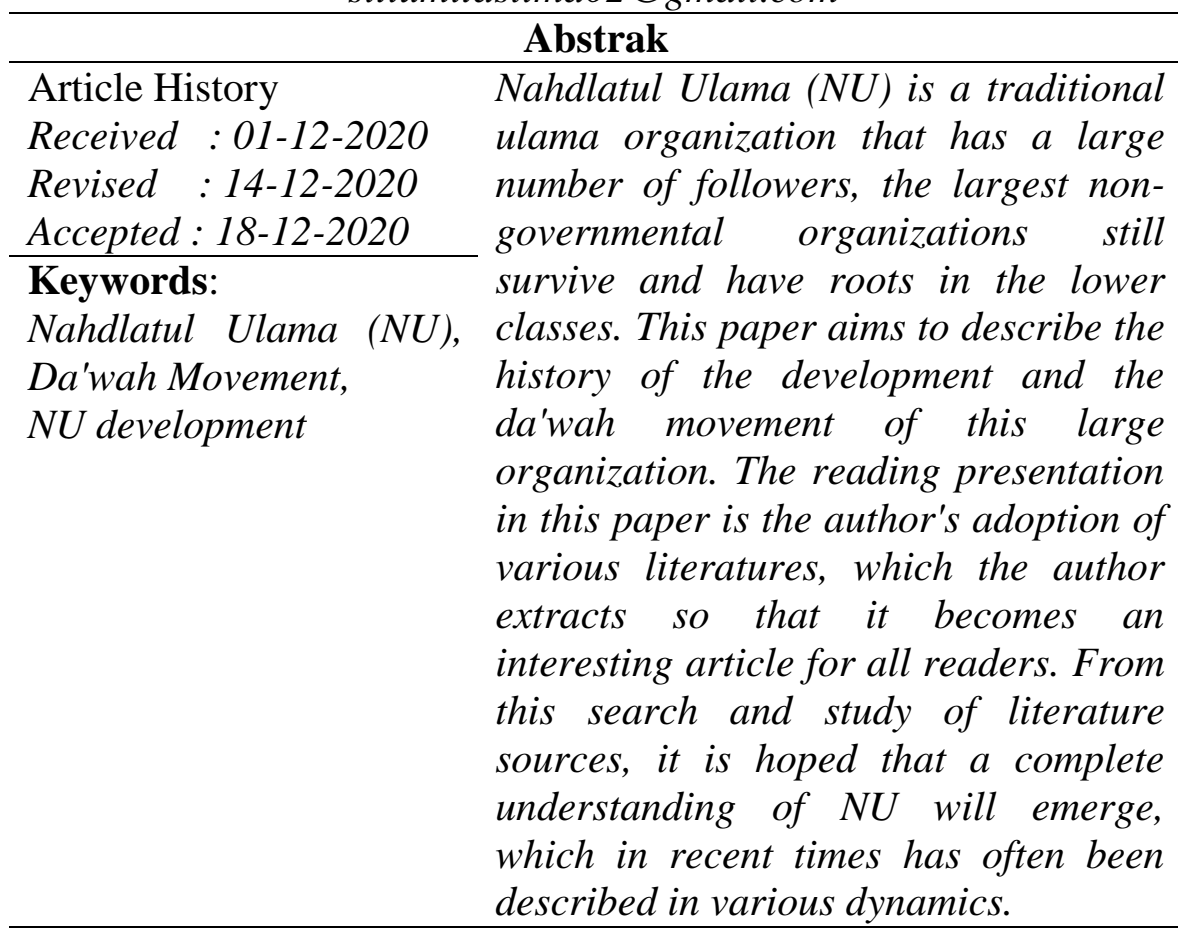

\section{Pendahuluan}

Sejarah lahirnya Nahdlatul Ulama (baca:NU) disebabkan beberapa faktor, di antaranya adanya perkembangan dan pembaruan dalam pemikiran Islam yang berkaitan dengan larangan yang dilakukan kaum Sunni dalam melakukan ibadah. Pembaruan pemikiran tersebut membawa kepada ajaran Islam yang sebenarnya atau yang dapat disebut dengan pemurnian (purifikasi), yaitu umat Islam tidak menggunakan sistem madhzab. Namun, hal itu tidak dapat dilakukan di kalangan pesantren karena menurut para kyai pembaruan dari segi pemikiran keagamaan masih dianggap suatu keniscayaan dengan tidak meninggalkan tradisi-tradisi para ulama yang masih 
bernilai secara keilmuannya. Demikian, berdasarkan hal tersebut secara mendesak Nahdlatul Ulama segera didirikan dengan dasar pendapat para ulama kaum tradisionalis yakni al-muhafadzah 'ala alqadim as-shalih wa al-akhdhu bi al-jadid al-ashlah.

Secara historis, berdirinya NU salah satu dari bagian reaksi antipembaru dari kaum ulama. Senada dengan hal tersebut, munculnya kaum reformis di Surabaya bukanlah penyebab utama dari berdirinya NU, namun dengan berdasarkan tujuan awal pada pertengahan tahun 1920-an yang berkaitan erat pada hubungan perkembangan internasional, penghapusan jabatan khalifah, serbuan kaum Wahabi atas Mekah dan pencarian suatu internasionalisme Islam yang baru. Dampak yang akan mempengaruhi kaum tradisionalis Indonesia yaitu menegakkan tata cara ibadah keagamaan yang selalu dipertanyakan oleh kaum Wahabi puritan, seperti membangun kuburan, ziarah kubur, membaca doa seperti dalail alkhairat, juga kepercayaan terhadap wali (Martin van Bruinessen, 2008: 23).

Menariknya, di Indonesia saat ini tengah terjadi berbagai dinamika di tengah keberadaan organisasi keagamaan, khususnya apa yang terjadi kepada NU. Berbagai isu ditimpakan kepada organisasi ini, mulai dibenturkan dengan organisasi keagamaan lainnya sampai isu perpecahan di dalam tubuh organisasi itu sendiri. Meskipun keadaan di atas tidak terlalu berpengaruh terhadap organisasi ini, namun harus diakui bahwa di garis bawah, masyarakat atau ummat mengalami dinamika dan pandangan masing-masing.

Melihat dinamika yang ada, penulis tertarik untuk menggali sumber-sumber yang berkaitan dengan organisasi NU, dan menuangkan dalam sebuah artikel ilmiah dengan maksud untuk memberikan deskripsi konkrit tentang Nahdlatul Ulama. Literatur yang ada tidak hanya diambil dari karya dari insider dari kalangan NU saja, namun juga dengan memperhatikan beberapa karya dan kritik yang berasal dari luar kalangan NU (outsider), bahkan berasal dari penulis internasional yang konsen terhadap organisasi keagamaan di Indonesia termasuk NU. Dengan demikian tulisan ini diharapkan menjadi sebuah sumber referensi bagi para penulis atau masyarakat yang ingin mengenal NU lebih jauh. 


\section{Metode Penelitian}

Penelitian ini menggunakan jenis penelitian studi kepustakaan atau library research, yakni suatu kegiatan pengumpulan data dan informasi dari berbagai sumber yang berkaitan dengan Nahdlatul Ulama. Telaah literatur ini dilakukan sebagai bentuk pemecahan suatu masalah dengan dasar yang berlandaskan pada pengkajian secara kritis dan mendalam terhadap materi-materi kepustakaan yang signifikan dengan NU. Sumber data yang terdapat pada tulisan ini berupa buku, artikel penelitian, serta dokumen lainnya yang ada kaitannya dengan NU. Langkah berikutnya yang dilakukan setelah data yakni melakukan analisis data yang ada untuk ditarik pada sebuah deskripsi kompleks. Dalam hal analisis data, penulis dalam hal ini menggunakan teknik analisis isi agar dapat diperoleh hasil yang relevan. Analisis isi (Content Analysis) dapat diartikan sebagai teknik membuat kesimpulan dengan cara mengidentifikasikan kekhususan dari teks secara objektif dan sistematis.

\section{Pembahasan}

\section{Sejarah Pemikiran Nahdlatul Ulama}

Nahdlatul Ulama (NU) merupakan suatu organisasi sosial keagamaan terbesar di Indonesia yang berdiri pada tanggal 16 Rajab $1344 \mathrm{H}$ atau 31 Januari $1926 \mathrm{M}$ di Surabaya oleh beberapa ulama termashyur. Tujuan didirikan NU dengan berpegang akidah Islam faham Ahlussunnah wal Jama'ah serta menganut salah satu madzhab empat: Hanafi, Maliki, Syafi'i dan Hambali. Beberapa hal yang melatar belakangi terbentuknya NU yaitu bersifat langsung ataupun tidak langsung (M. Ali Haidar, 1994: 40). Contohnya, munculnya pemikiran Pan-Islamisme dari gerakan pembaruan di Mesir dan sebagian Timur Tengah lainnya yang dipimpin oleh Jamaluddin alAfghani dengan tujuan untuk mempersatukan seluruh dunia Islam. Di sisi lain, kebangkitan gerakan nasionalisme digunakan untuk menjatuhkan Khilafah Usmaniyyah di Turki.

Gerakan pembaruan di Mesir dan Turki diakibatkan oleh kesadaran sosial politik karena Barat lebih maju dari pada dunia Islam. Gerakan Wahabi yang muncul di Arab Saudi bergelut dalam persoalan dari dalam diri umat Islam itu sendiri, berupa pembaruan 
dari segi doktrin ketauhidan serta perlindungan bidang hukum dengan asumsi bahwa ajaran umat Islam telah dirusak oleh khurafat serta kemusyrikan. Begitu pula yang terjadi di Indonesia, banyak berdiri organisasi-organisasi sosial dalam bidang kebangsaan maupun keagamaan dengan maksud menjadikan kehidupan umat lebih maju. Misalnya, oraganisasi Budi Utomo (20 Mei 1908), Syarekat Islam (11 Nopember 1912) yang sebelumnya bernama Syarekat Dagang Islam (SDI) dan kemudian disusul Muhammadiyah (18 Nopember 1912).

Dari masalah yang dihadapi umat Islam di atas memberikan dampak pada bangkitnya semangat para pemuda Islam di Indonesia dalam membentuk sebuah organisasi yang berfokus pada bidang pendidikan dan juga da'wah, antara lain berdirinya Nahdlatul Wathan pada tahun 1914 yang diartikan sebagai kebangkitan tanah air dan Taswirul Afkar yang berdiri pada tahun 1918 dengan arti potret pemikiran. KH. Abdul Wahab Hasbullah dan Mas Mansur merupakan pelopor dari berdirinya kedua organisasi tersebut. Madrasah Nahdlatul Wathan didirikan oleh KH. Abdul Wahab Hasbullah pada tahun 1916 dengan bangunan gedung yang terlihat besar dan bertingkat berada di Surabaya. Selain itu, para pemuda digembleng di dalam gedung madrasah tersebut yang selanjutnya terbentuk organisasi Jam'iyyatun Nasihin yaitu organisasi yang ditujukan para pendakwah. Tidak hanya di Surabaya, madrasah Nahdlatul Wathan juga mendirikan cabang di kota lain, seperti Malang, Semarang, Gresik, Jombang serta beberapa daerah yang ada di Surabaya. Cabang-cabang madrasah tersebut ada yang masih memakai nama Nahdlatul Wathan, dan juga memberikan nama sendiri, contohnya madrasah Far'ul Wathan, Hidayatul Wathan, Khitabatul Wathan maupun Akhul Wathan. Selain mendirikan madrasah, KH. Abdul Wahab Hasbullah juga mendirikan organisasi Nahdlatut Tujjar yakni sebuah koperasi yang dapat digunakan oleh para pedagang pada tahun 1918 (Ahmad Zahra, 2004: 16). Pada awal tahun 1919 di daerah Ampel berdirilah sebuah madrasah menggunakan nama Taswirul Afkar dengan maksud untuk memberikan tempat kepada anak-anak yang mengaji maupun belajar yang bertujuan agar di masa depan nantinya menjadi sayap pembela kepentingan Islam tradisionalis.

Langkah selanjutnya yaitu munculnya perbedaan-perbedaan sehingga memicu timbulnya perdebatan yang terjadi di antara kaum tradisionalis yang dipelopori oleh KH. Abdul Wahab Hasbullah serta pengikutnya yang lain dengan kaum reformis yang dipimpin oleh 
Achmad Soorkati sebagai pendiri al-Irsyad dan KH. Ahmad Dahlan sebagai pendiri Muhammadiyah yang terus semakin menjadi pada awal tahun 1920. Perdebatan antara kedua kelompok tersebut semakin memuncak pada Kongres al-Islam yang diselenggarakan tahun 1922 di Cirebon dengan semakin serunya terdengar tuduhan kafir dan syirik pada kaum tradisionalis. Selanjutnya, yang terjadi pada bulan Januari 1926, di mana sebelum diadakan Kongres al-Islam di Bandung yakni rapat yang dilakukan oleh organisasi pembaru di Cianjur dengan hasil adanya putusan untuk mengirim dua orang utusan ke Mekah. Gagasan KH. Abdul Wahab yang disampaikan dalam Kongres al-Islam pada bulan Februari tahun 1926 supaya saran-saran dari kaum tradisionalis yang berkaitan dengan praktek keagamaan agar dibawa delegasi Indonesia. Namun, tidak mendapat persetujuan dari kaum reformis. Penolakan tersebut memberikan dampak kepada kaum tradisionalis dengan menempuh jalan tersendiri dalam memperjuangkan gagasan tentang tradisi keagamaan kepada Raja Ibn Sa'ud di Mekah. Dalam mempermudah perjalanan dalam menunaikan tugasnya, maka dibentuklah Komite Hijaz pada 31 Januari 1926/16 Rajab 1344 dengan mengadakan rapat, sehingga keputusan tersebut tercetus pembentukan suatu organisasi yang berbasis masyarakat Islam yakni Nahdlatul Ulama atau kebangkitan ulama dengan ajaran Ahlussunnah wal Jama'ah. (Ahmad Zahra, 2004: 18).

\section{Konsep Gerakan Dakwah Nahdlatul Ulama}

\section{Tokoh-Tokoh Gerakan Dakwah NU}

Beberapa tokoh sentral NU diantaranya K.H. Hasyim Asy'ari, K.H. Abdul Wahab Hasbullah serta para ulama pada masa. Di mana perkembangan kaum reformasi begitu pesat, sedangkan kaum ulama secara keseluruhan belum terorganisir tetapi memiliki hubungan yang kuat antara satu sama lain. Peringatan yang ada di kalangan pesantren seperti haul yang dimaknai sebagai tradisi mengenang wafatnya kyai yang diadakan setahun dengan cara mengumpulkan para kyai, masyarakat sekitar pesantren maupun para murid pesantren yang dulunya mondok di pesantren tersebut, yang mana mereka saat ini telah tersebar di seluruh wilayah Nusantara (Masykur Hasyim, 2002: 66). 
Tokoh NU yang pertama yaitu Muhammad Hasyim yang lebih dikenal dengan sebutan KH. Hasyim Asy'ari, tempat lahir di desa Gedang, Jombang, Jawa Timur pada tanggal 24 Zulkaidah $1287 \mathrm{H}$ atau 14 Februari 1871. Beliau wafat di Jombang pada Juli 1947. KH. Hasyim Asy'ari dengan garis keturunan kyai, di mana Kyai Sihah merupakan kakek buyutnya, seorang pendiri Pondok Pesantren Tambak Beras, di sisi lain Kyai Usman adalah kakeknya yakni seorang kyai termashur sebagai pendiri pondok pesantren Gedang, ayahnya sendiri yakni Asy'ari dikenal sebagai pengasuh pondok pesantren Keras di Jombang. (Ishomuddin Hadziq, 2007: 12).

Ibu KH Hasyim Asy'ari yaitu Halimah yang mempunyai 10 anak, dan beliau sendiri merupakan putra ketiga. Kesepuluh saudaranya antara lain: Nafi'ah, Ahmad Saleh, Radiah, Hassan, Anis, Fatanah, Maimunah, Maksum, Nahrawi dan Adnan. Dengan melihat garis keturunan dari ibunya, KH. Hasyim Asy'ari adalah keturunan dari Sultan Pajang Jaka Tingkir yang merupakan keturunan dari raja Hindu Majapahit yakni Raja Brawijaya V atau yang biasa dikenal dengan sebutan Lembupeteng. Selama hidupnya KH. Hasyim Asy'ari telah menikah sebanyak tujuh kali, di mana dari semua istrinya merupakan putri dari para ulama. Di antara nama-nama istrinya yaitu Khadijah, Nafisah, Nafiqah, dan Masrurah. Salah seorang putra dari KH. Hasyim Asy'ari adalah Wahid Hasyim yang ikut berperan penting dalam perumusan Piagam Jakarta dan selanjutnya menjadi Menteri Agama. Kemudian cucunya sendiri yang bernama Abdurrahman Wahid dilantik menjadi Presiden Indonesia. (Greg Barton, 2002: 26).

Dengan melihat garis keturunan tersebut bahwa KH. Hasyim Asy'ari yang lahir dan dibesarkan di lingkungan pondok pesantren. Prestasi yang membanggakan yaitu saat menginjak usia ke 13 tahun ia dapat menguasai kitab-kitab Islam klasik yang kemudian diangkat menjadi badal (asisten pengajar) di pondok pesantren Keras. Saat usia 15 tahun, Hasyim Asy'ari kecil mulai mengikuti pengembaraan yang diadakan pesantren-pesantren yang ada di pulau Jawa dengan tujuan memperdalam ilmu agama, di antaranya Pesantren Wonocolo Jombang, Pesantren Probolinggo, Pesantren Langitan, Pesantern Tranggilis, yang akhirnya berguru kepada Kyai Kholil yang berada di daerah Bangkalan, Madura. 
Perjalanan dalam rangka memperdalam ilmu keagamaan $\mathrm{KH}$. Hasyim Asy'ari berkelana ke Mekah pada tahun 1893 dengan menimba ilmu kepada Syekh Mahfudh At-Tarmisi yang berasal dari Tremas, Jawa Timur. Syekh Mahfudh At-Tarmisi sendiri adalah seorang pengajar di Masjidil Haram serta salah satu ulama ahli hadits di Mekah, beliau merupakan murid dari Syekh Nawawi Al-Bantany yang menjadi murid Syekh Ahmad Khatib Syambasi yaitu seorang tokoh ahli tasawuf dengan keberhasilannya dalam menggabungkan kedua tarikat yakni Qadariah dan Naqsabandiah (Imron Arifin, 1983: 71). Sebagai pelengkap dalam mencari ilmu pengetahuan agama, KH. Hasyim Asy'ari selanjutnya berguru kepada Syekh Ahmad Khatib Al-Minangkabau. Dari sekian banyak guru yang telah didatanginya, Syekh Mahfudh At-Tarmisi adalah guru yang mampu mempengaruhi jalan pikiran KH. Hasyim Asy'ari. Dari gurunya inilah dia memperoleh ijazah tarikat Qadariah dan Naqsabandiah.

Setelah 7 tahun belajar di Mekah, KH. Hasyim Asy'ari pulang ke Jawa dan mendirikan pondok Pesantren Tebu Ireng di Jombang pada 26 Rabiul Awal 1317 H/1899 M. Di pondok pesantren inilah KH. Hasyim Asy'ari mengajarkan kitab-kitab klasik kepada santrinya yang oleh kalangan NU dikenal dengan "kitab kuning". Dari pesantren ini pula kemudian banyak bermunculan kyai dan ulama terkemuka yang mewarnai pemikiran Islam di Indonesia.

Tokoh NU yang kedua yaitu KH. Abdul Wahab Hasbullah atau yang biasa dikenal dengan nama Mbah Wahab merupakan putra pertama dari KH. Hasbullah. Beliau lahir di Desa Tambak Beras, Jombang Jawa Timur pada tahun 1888 M. Secara geneologi, ayahnya merupakan putra dari Kyai Said yaitu cucu dari Kyai Abdus Salam, seorang pendiri Pesantren Selawe dan Telu. (Soeleiman \& Subhan, 2007: 296).

Kyai Said menikah dengan Fatimah dan memiliki keturunan empat orang anak dengan tiga orang putra dan satu orang putri yaitu Kyai Hasbullah, Kyai Syafi'i, Kyai Asim, dan putrinya yang tidak disebutkan namanya. Kemudian Kyai Hasbullah menikah dengan Nyai Lathifah. Dari pernikahan tersebut dikaruniai delapan orang anak, di antaranya tiga orang putra dan lima orang putri, yaitu $\mathrm{KH}$. Abdul Wahab Hasbullah, Kyai Abdul Hamid, Kyai Abdur Rohim, Khodijah, Fatimah, Solihah, Zuhriyah, dan Aminaturrokhiyah. Dibandingkan dengan saudara-saudaranya yang lain, Kyai Abdul 
Wahab Hasbullah lebih menonjol dan banyak dikenal orang. (Choirul Anam, 2017: 100).

Dalam bidang pendidikan KH. Abdul Wahab Hasbullah mulai belajar dari kecil sampai besar semuanya hanya di lingkungan pesantren. Artinya, ia adalah anak didik sistem pendidikan Islam tradisional. Ketika kecil, ayahnya Kyai Said mengajarkan pelajaran agama kepadanya secara sungguh-sungguh agar mendapatkan hasil dan pemahaman yang maksimal. Setelah dianggap cukup mampu menguasai dasar-dasar ilmu agama, ayahnya mengirimkan $\mathrm{KH}$. Abdul Wahab Hasbullah ke Pesantren Langitan, Tuban yang saat itu dibawah asuhan Kyai Ahmad Sholeh. Kemudian melanjutkan pendidikan di Pesantren Mojosari yang berada di daerah Nganjuk, selanjutnya di Pesantren Tawangsari Sepanjang, beliau juga memperdalam ilmunya kepada Syaikhona R. Muhammad Kholil Bangkalan, Madura, serta belajar di Pesantren Tebuireng Jombang yang saat itu KH. Hasyim Asy'ari sebagai pengasuhnya. Di Pondok Pesantren tersebut KH. Abdul Wahab Hasbullah belajar dan memperdalam ilmu agama, hingga usianya mencapai 21 tahun. Meskipun banyak yang menyebutnya sebagai "Kyai Muda"18 akan tetapi ayahnya masih menganggapnya belum cukup dan masih perlu belajar lagi. Untuk itu pada tahun 1909 M, ia diberangkatkan oleh ayahnya ke Mekah untuk lebih mem-perdalam keilmuan agamanya.

Di Mekah KH. Abdul Wahab Hasbullah berguru kepada Kyai Mahfudz Termas yang memiliki julukan Al-Turmusi terutama dalam keilmuan hukum, Tasawwuf dan Ushul-fiqh. Selain berguru kepada Kyai Mahfudz Termas, ia juga berguru kepada Kyai Muchtarom Banyumas dalam mempelajari kitab Fathul Wahab, selanjutnya kepada Syaikh Sa'id Al-Yamani dalam keilmuan Nahwu (Usymuni) dan Syaikh Ahmad bin Bakry Syatha. KH. Abdul Wahab Hasbullah berguru lagi kepada Syaikh Ahmad Khatib Minangkabau, di mana pada waktu itu diangkat sebagai Mufti Syafi'i di Mekah. Kemudian kepada Kyai Baqir yang berasal dari Yogya, ia belajar mengenai ilmu mantik (logika) dan kepada Kyai Asy'ari yang berasal dari Bawean, ia memperdalam ilmu Hisab. Dan ia berguru lagi kepada Syaikh Abdul Karim Ad-Daghestany untuk menyelesaikan kitab Tuhfah. Selanjutnya kepada Syaikh Abdul Hamid yang berasal dari Kudus, ia belajar mengenai 'Arudh dan Ma'ani. Kepada Syaikh Umar Bajened untuk memperdalam ilmu Fiqh. (Choirul Anam, 2017: 97). 


\section{Karya-Karya Tokoh NU}

Adapun karya tulis yang dihasilkan oleh KH. Hasyim Asy'ari di antaranya yaitu:

a. Al-Tibyan fi al-Nahy dan Muqata'at al-Arham wa al-Aqarib wa al-Akhawan. Dalam buku tersebut berisikan penjelasanpenjelasan yang berkaitan dengan larangan memutuskan hubungan kerabat dan persahabatan.

b. Adab al-Alim wa al-Muta'allim. Isi dari buku ini yaitu menjelaskan tentang akhlak guru dan murid, di antaranya etika dalam belajar serta pentingnya ilmu pengetahuan.

c. Al-Tanbihat al-Wajibat li Man Yasna'al al-Mawlid bi alMunkarat. Penjelasan yang terdapat dalam buku mengenai nasehat penting tentang perayaan kelahiran Nabi Muhammad yang dianggap bertentangan dengan ajaran agama.

d. Risalah Ahl al- Sunnah Wa al-jama'ah. Buku yang menjelaskan berbagai topik, di antaranya kematian, kemudian hari kebangkitan, antara arti sunnah dan bid'ah. Selain itu masih banyak lagi karangan yang ditulis oleh KH. Hasyim Asy'ari. (Muh. Nasir, 2011: 41-42).

KH. Abdul Wahab Hasbullah bukanlah seperti kiai yang lain, yang banyak menciptakan karir yang tertulis. Salah satu karyanya yaitu menciptkan syair berbahasa Arab yang berjudul "Yaa Lal Wathon". Syair tersebut dijadikan sebagai lagu oleh pondok Pesantren di Jawa Timur. Bila diterjemahkan dalam bahasa Arab dan bahasa Indonesia, sebagai berikut:

Ya Lal Wathon Ya Lal Wathon Ya Lal Wathon

Hubbul Wathon minal Iman

Wala Takun minal Hirman

Inhadlu Alal Wathon

Indonesia Biladi

Anta 'Unwanul Fakhoma

Kullu May Ya'tika Yauma

Thomihay Yalqo Himama 
"Hai patriot bangsa, hai patriot bangsa. Cinta tanah itu bagian dari iman. Cintailah tanah air-mu, wahai patriot bangsa. Janganlah kalian menjadi bangsa terjajah. Sungguh kemuliaan itu hanya bisa dicapai dengan tindakan. Bukan hanya dengan katakata. Maka berbuatlah untuk menggapai cita-cita. Dan jangan cuma bicara. Duniamu bukan tempat untuk menetap. Tapi Cuma tempat buat berlabuh. Maka berbuatlah sesuai yang Dia perintahkan. Jangan mau jadi sapi perahan. Kalian tak tahu siapa pemutar balik fakta. Kalian tak pikirkan apa yang telah berubah. Di mana perjalanan akan berakhir. Bagaimana peristiwa bisa berakhir. Atau mereka memberimu minum. Juga kepada ternakmu. Atau mereka melepaskanmu dari beban. Ataukah malah menenggelamkanmu dalam beban. Hai, pemilik pikiran yang jernih. Hai, pemilik hati yang lembut. Jadilah orang yang tinggi cita-cita. Jangan jadi ternak gembala". (Choirul Anam, 2017: 210)

Syair yang kemudian menjadi nyanyian tersebut dianggap sebagai salah satu karya KH. Abdul Wahab Hasbullah yang nyata berupa tulisan, karena tidak ada karyanya yang lain selain itu.

\section{Ideologi Gerakan NU}

Nahdlatul Ulama yang dikenal sebagai suatu organisasi keagamaan dan kemasyarakatan, prinsip-prinsip yang dilakukan NU berkaitan erat dengan usaha dalam pemahaman serta pengamalan ajaran Islam, yaitu berhubungan dan berkomunikasi baik secara vertikal dengan Allah SWT ataupun secara horisontal berhubungan baik dan menjalin komunikasi antara sesama manusia.

Paham keagamaan yang dianut oleh NU mendasarkan bersumber pada ajaran Islam, yakni Al-Qur'an dan as-Sunnah, alijma' dan al-qiyas. NU sendiri bermadzhab dengan mengikuti salah satu dari empat madzhab yaitu Hanafi, Maliki, Syafi'i, dan Hambali dengan penentuan dasar-dasar dalam penetapan hukum masingmasing madzhab serta tidak hanya terbatas pada empat hal di atas. Keempat sumber yang dimaksud di atas adalah dasar-dasar penetapan hukum madzhab Syafi'i, maka ada benarnya. Jika Al-Qur'an, asSunnah, al-ijma' dan al-qiyas dianggap sebagai sumber tentu kurang tepat karena sumber ajaran islam hanya Al-Qur'an dan as-Sunnah. Sedangkan al-ijma' dan al-qiyas adalah metode istinabat hukum atau dasar-dasar penetapan hukum dan bukan sumber hukum itu sendiri. 
Nahdlatul Ulama sebagai pengikut paham Ahlussunnah wal Jama'ah secara keseluruhan menggunakan pemahaman serta penafsiran ajaran Islam yang terletak sumber-sumbernya dengan pendekatan madzhabiy atau menggunakan madzhab :

a. Bidang aqidah, NU mengikuti paham Ahlussunnah wal Jama'ah yang dipelopori Abdul Hasan al-Asy'ari (260-324 H/873-935 M) dan Abu Mansur al-Maturidi (w. 333 H/944 M).

b. Bidang fiqh, NU mengikuti salah satu madzhab empat, yaitu Abu Hanifah an-Nu'man (80-150 H/700-767 M), Malik bin Anas (90174 H/ 711-795 M) dan Ahmad bin Hambal (164-241 H/780-885 M), atau Imam Asy-Syafi'i (150-205H/ 767-820M)

c. Bidang tasawuf, NU mengikuti antara lain al-Junaid al-Baghdadi (w. $297 \mathrm{H}$ ) dan Abu Hamid al-Ghazali (450-505 H/1058-1111 M). (Ahmad Zahra, 2004: 19)

\section{Strategi Dakwah NU}

Dalam strategi dakwah Nahdlatul Ulama, metode yang digunakan adalah Wali Songo dengan menggunakan pendekatan budaya yang diyakini sebagai unsur penting dalam melakukan dakwah Islam di Nusantara. Di antaranya dengan menggunakan pendekatan tersebut agama Islam dapat diterima baik oleh penduduk pribumi pada saat kedatangan Islam pertama kalinya. Di sisi lain kebudayaan Islam berbasis lokal pada saat ini semakin terancam oleh bermacam-macam budaya serta ideologi yang bermunculan baik dari kalangan barat maupun kalangan timur. Sehingga yang terjadi adalah bagaimana usaha yang dapat dilakukan dalam perjuangan mempertahankan budaya dengan cara mengenalkan Islam yaitu agama dengan menciptakan kedamaian serta cinta keindahan.

Upaya-upaya NU dalam melakukan akulturasi budaya merupakan sebuah khittah organisasi yang kuat. Di antaranya melalui usaha sosialiasi ke pondok pesantren dengan menggukan basis kaderisasi yang mumpuni di kalangan NU. Selain itu, hal-hal yang dapat dilakukan dengan cara memberi penyadaran khususnya warga nahdliyyin terkait pentingnya budaya dalam melakukan dakwah. Secara garis besar NU sendiri lebih fokus kepada kaderisasi yang digunakan sebagai gerakan cultural serta NU tidak masuk wilayah politik. 
Banyak media pendukung dalam melakukan pendekatan budaya, di antaranya media yang berkembang di era sekarang salah satunya melalui film dalam penyampaian dakwah berbasis kebudayaan. Tetapi, harus diakui bahwa kiprah warga nahdliyin dalam seni budaya dan perfilman di Indonesia masih tergolong lemah. Faktanya, pada era 70-an, di mana masa tersebut banyak bermunculan berbagai macam karya seni yang dihasilkan dan disumbangkan oleh kalangan nahdliyyin sebagai kekuatan budaya.

Dalam buku yang berjudul Ahlussunnah Wal-Jama'ah; dalam Persepsi dan Tradisi NU karangan Muhammad Tholhah Hasan berpendapat bahwa dapat memahami Ahlussunnah wal Jama'ah secara keseluruhan, pendekatan doctrinal saja masih kurang, untuk itu ada tiga macam pendekatan yang dapat digunakan, antara lain:

a. Pendekatan Historis, yaitu menggunakan ajaran agama secara teoritis dengan berlatar belakang perjalanan yang telah dilakukan umat Islam sejak zaman Rasulullah saw sampai zaman sekarang. Dengan begitu konsep yang dilahirkan Ahlussunnah wal Jama'ah ini berdasarkan aqidah yang kuat yaitu tauhid dengan menggunakan prinsip-prinsip keimanan yang kekal, namun dalam perwujudan perumusan konseptualnya dapat berbeda.

b. Pendekatan Kultural, Di tengah-tengah pergumulan pemikiran yang demikian (intelektualitas dan religiusitas), para ulama dan pemikir Ahlusunnah wal Jama'ah mengambil posisi baru, dari pendekatan Salaf yang mencukupkan diri dengan dalil-dalil Naqliyah, menjauhi ta'wil dan tafsir ayat-ayat mutasyabihat dengan sikap tafwidl (penyerahan total) ke pendekatan Kholaf (yang menggunakan dalil-dalil 'aqliyah disamping dalildalil naqliyah, melakukan penafsiran ayat-ayat mutasyabihat yang lebih mudah dicerna awam dan lebih menyelamatkan mereka dari jebakan faham tasybih/penyerupaan Tuhan dengan sifat makhluk, dan mentolelir sistem ta'wil secara kritis dan hati-hati). Disinilah tokoh-tokoh Ahlussunnah wal Jama'ah seperti Imam Abu Hasan Al-Asy'ari dan Abu Manshur Al-Maturidi serta para pengikutnya berperan.

c. Pendekatan Doktrinal, identitas kelompok merupakan awal dari terbentuknya paham Ahlussunnah wal Jama'ah dalam dimensi teologis maupun aqidah Islam yang berpusat pada masalah ushuluddin. Namun, seiring berjalannya waktu tidak mampu terlepas dari aspel keislaman yang lain, misalnya pada aspek 
Syari'ah Fiqhiyah maupun yang terjadi pada aspek Tasawuf. Selain itu, permasalah budaya, politik dan social merupakan suatu kaitan yang erat hubungannya dengan cabang dan rantingnya dalam ajaran aqidah (Tholhah Hasan, 2005: xiii-xviii).

\section{Lembaga-Lembaga NU}

Lembaga dapat diartikan sebagai perangkat dalam menyusun satuan organisasi Nahdlatul Ulama dengan tujuan sebagai pelaksana kebijakan Nahdlatul Ulama yang berfokus pada kelompok masyarakat tertentu maupun kepada masyarakat yang memerlukan penanganan khusus. Lembaga-lembaga NU antara lain:

a. Lembaga Dakwah Nahdlatul Ulama disingkat LDNU, bertugas melaksanakan kebijakan Nahdlatul Ulama di bidang pengembangan agama Islam yang menganut faham Ahlussunnah wal Jamaah.

b. Lembaga Pendidikan Maarif Nahdlatul Ulama disingkat LP Maarif NU, bertugas melaksanakan kebijakan NU dalam bidang pendidikan dan pengajaran formal.

c. Rabithah Ma'ahid al Islamiyah Nahdlatul Ulama disingkat RMI NU, bertugas melaksanakan kebijakan Nahdlatul Ulama dibidang pengembangan pondok pesantren dan pendidikan keagamaan.

d. Lembaga Perekonomian Nahdlatul Ulama disingkat LPNU bertugas melaksanakan kebijakan Nahdlatul Ulama di bidang pengembangan ekonomi warga Nahdlatul Ulama.

e. Lembaga Pengembangan Pertanian Nahdlatul Ulama disingkat LPPNU, bertugas melaksanakan kebijakan Nahdlatul Ulama di bidang pengembangan dan pengelolaan pertanian, kehutanan dan lingkungan hidup.

f. Lembaga Kemaslahatan Keluarga Nahdlatul Ulama disingkat LKKNU, bertugas melaksanakan kebijakan Nahdlatul Ulama di bidang kesejahteraan keluarga, sosial dan kependudukan.

g. Lembaga Kajian dan Pengembangan Sumberdaya Manusia Nahdlatul Ulama disingkat LAKPESDAM NU, bertugas melaksanakan kebijakan Nahdlatul Ulama di bidang pengkajian dan pengembangan sumber daya manusia.

h. Lembaga Penyuluhan dan Bantuan Hukum Nahdlatul Ulama disingkat LPBHNU, bertugas melaksanakan pendampingan, penyuluhan, konsultasi, dan kajian kebijakan hukum. 
i. Lembaga Seni Budaya Muslimin Indonesia Nahdlatul Ulama disingkat LESBUMI NU, bertugas melaksanakan kebijakan Nahdlatul Ulama dibidang pengembangan seni dan budaya.

j. Lembaga Amil Zakat, Infaq dan Shadaqah Nahdlatul Ulama disingkat LAZISNU, bertugas menghimpun, mengelola dan mentasharufkan zakat dan shadaqah kepada mustahiqnya.

k. Lembaga Waqaf dan Pertanahan Nahdlatul Ulama disingkat LWPNU, bertugas mengurus, mengelola serta mengembangkan tanah dan bangunan serta harta benda wakaf lainnya milik Nahdlatul Ulama.

1. Lembaga Bahtsul Masail Nahdlatul Ulama disingkat LBMNU, bertugas membahas masalah-masalah maudlu'iyah (tematik) dan waqi'iyah (aktual) yang akan menjadi Keputusan Pengurus Besar Nahdlatul Ulama.

m. Lembaga Ta'mir Masjid Nahdlatul Ulama disingkat LTMNU, bertugas melaksanakan kebijakan Nahdlatul Ulama di bidang pengembangan dan pemberdayaan Masjid.

n. Lembaga Kesehatan Nahdlatul Ulama disingkat LKNU, bertugas melaksanakan kebijakan Nahdlatul Ulama di bidang kesehatan.

o. Lembaga Falakiyah Nahdlatul Ulama disingkat LFNU, bertugas mengelola masalah ru'yah, hisab dan pengembangan ilmu falak.

p. Lembaga Ta'lif wan Nasyr Nahdlatul Ulama disingkat LTNNU, bertugas mengembangkan penulisan, penerjemahan dan penerbitan kitab/buku serta media informasi menurut faham Ahlussunnah wal Jamaah.

q. Lembaga Pendidikan Tinggi Nahdlatul Ulama disingkat LPTNU, bertugas mengembangkan pendidikan tinggi Nahdlatul Ulama.

r. Lembaga Penanggulangan Bencana dan Perubahan Iklim Nahdlatul Ulama disingkat LPBI NU, bertugas melaksanakan kebijakan Nahdlatul Ulama dalam pencegahan dan penanggulangan bencana serta eksplorasi kelautan. (PCNU Bogor, 2015: 5-6).

\section{Simpulan}

Nahdlatul Ulama merupakan suatu organisasi keagamaan Islam yang berdiri pada tanggal 16 Rajab $1344 \mathrm{H}$ atau 31 Januari 1926 M di kota Surabaya yang dipelopori oleh KH. Hasyim Asy'ari, KH. Abdul Wahab Hasbullah. Karya-karya yang ditulis oleh KH. Hasyim Asy'ari sebagai berikut: Al-Tibyan fi al-Nahy dan Muqata'at 
al-Arham wa al-Aqarib wa al-Akhawan, Adab al-Alim wa alMuta'allim, Al-Tanbihat al-Wajibat li Man Yasna'al al-Mawlid bi alMunkarat, Risalah Ahl al- Sunnah Wa al-jama'ah. Sedangkan karya yang dihasilkan oleh KH. Abdul Wahal Hasbullah yaitu syair berbahasa Arab yang berjudul "Yaa Lal Wathon". NU menganut paham Ahlussunnah wal Jama'ah dengan mendasarkan paham keagamaannya kepada sumber ajaran Islam, yaitu Al-Qur'an dan asSunnah, al-ijma' dan al-qiyas. dan mengikuti mazhab salah satu dari empat mazhab: Hanafi, Maliki, Syafi'i dan Hambali. Strategi dakwah yang dilakukan Nahdlatul Ulama metode yang digunakan Wali Songo dulu. NU berkomitmen memperkuat pendekatan budaya sebagai salah satu elemen penting dakwah Islam di Tanah Air. NU melakukan berbagai upaya agar akulturasi budaya tersebut tetap menjadi khittah kuat organisasi. Dalam dakwah NU menggunakan tiga pendekatan yaitu pendekatan historis, kultural dan juga doktrinal. Banyak lembaga yag didirikan oleh Nahdlatul Ulama yang berfungsi sebagai pelaksana kebijakan NU, berkaitan dengan kelompok masyarakat tertentu maupun yang memerlukan penanganan khusus, sebagai contohnya lembaga dakwah Nahdlatul Ulama (LDNU), lembaga pendidikan Ma'arif NU, dan lain-lain. 


\section{DAFTAR PUSTAKA}

Haidar, M. Ali. 1994. Nahdlatul Ulama dan Islam di Indonesia, Pendekatan Fikih dalam Politik. Jakarta: Gramedia.

Zahra, Ahmad. 2004. Tradisi Intelektual NU: Lajnah Bahtsul Masa'il 1926-1999. Yogyakarta: LKiS.

Bruinessen, Martin van. 2008. NU: Tradisi, Relasi-Relasi Kuasa, Pencarian Wacana Baru. Yogyakarta: LKiS.

Hasyim, Masykur. 2002. Merakit Negeri Berserakan. Surabaya: Yayasan 95.

Barton, Greg. 2002. Biografi Gus Dur: The Authorized Biography of Abdurrahman Wahid. Yogyakarta: LKiS.

Arifin, Imron. 1983. Kepemimpinan Kyai: Kasus Pondok Pesantren Tebu Ireng. Malang: Kalimasada Press.

Fadeli, Soeleiman dan Mohammad Subhan. 2007. Antologi NU BUKU 1: Sejarah-Istilah-Amaliah Uswah. Surabaya: Khalista.

Anam, Choirul. 2017. KH. Abdul Wahab Chasbullah: Hidup dan Perjuangannya. Surabaya: PT. Duta Aksara Mulia.

Nasir, Muh., 2011. KH. Hasyim Asy'ari: Peranan dan Pengaruhnya pada Pertengahan Pertama Abad Ke-20. Makassar: Alauddin University Press.

Hasan, Muhammad Tholhah. 2005. Ahlussunnah Wal-Jama'ah; dalam Persepsi dan Tradisi NU. Jakarta : Lantabora Press. 